\title{
On the kinetics of modified CVD in porous ceramics
}

\author{
G.Z. CAO, H.W. BRINKMAN, J. MEIJERINK, K.J. DE VRIES and A.J. BURGGRAAF \\ Laboratory of Inorganic Chemistry, Materials Science and Catalysis, Department of Chemical \\ Engineering, University of Twente, P.O. Box 217, 7500 AE Enschede, The Netherlands
}

\begin{abstract}
This paper reports a kinetic study on modified CVD process in porous ceramic substrates by both theoretical analysis and experimental approach. The theoretical analysis indicates that with a heterogeneous chemical reaction the decrease of the pore size is proportional to the deposition time and the pore closure time is proportional to the original pore size. While for a homogeneous reaction the pore size decreases exponentially with the deposition time and it is very difficult to achieve pore closure. The experimental results indicate that the deposition of YSZ in porous ceramics is a heterogeneous reaction.
\end{abstract}

\section{Introduction}

Porous ceramic membranes have attracted much attention in chemical industries for applications, such as gas separation and catalytic reactions, because of their unique characteristics, good chemical and thermal resistance, as well as excellent toughness [1]. For membrane applications proper surface chemistry, pore size and narrow pore size distribution are essential. With the sol-gel technique, ceramic membranes with nano-scale pore size can be synthesized. However, the preparation of ceramic membranes with pore size on the subnanometer scale remains very difficult without using silica. Recently so-called modified chemical vapour deposition (CVD) has been introduced to prepare and modify porous ceramic membranes [2-5]. This technique is the initial stage of the electrochemical vapour deposition (EVD), introduced by Westinghouse Electric Corporation [6] for the deposition of a thin dense oxide layer on top of a porous substrate. The modified CVD technique offers the possibility of modifying ceramic membranes, not only by reducing the pore size to the subnanometer scale, but also by coating the internal pore surface and thus modifying the membranes chemically. The principles of modified CVD have been described in detail in literature [2]. A porous membrane substrate (either a porous tube or plate) is placed in a CVD reactor chamber to separate a mixture of metal chloride vapours from the oxygen source reactant (water vapour and/or oxygen gas), as shown in Figure 1. The reactants counter-diffuse from both sides into the porous substrate and react to form a metal oxide, which deposits on the inner surface of pores and results in a reduction of pore size till eventually pore plugging. So it is possible that porous ceramic membranes, with desired pore size and inner pore surface chemical properties, can be prepared and modified by using the modified chemical vapour deposition (CVD) technique. A prolonged deposition will lead to the formation of a thin dense metal oxide layer on top of porous substrates by means of EVD.

The modified chemical vapour deposition (CVD) in porous ceramic membranes is in fact a combined process of counter-diffusion and chemical reactions of reactants inside the pores. The 


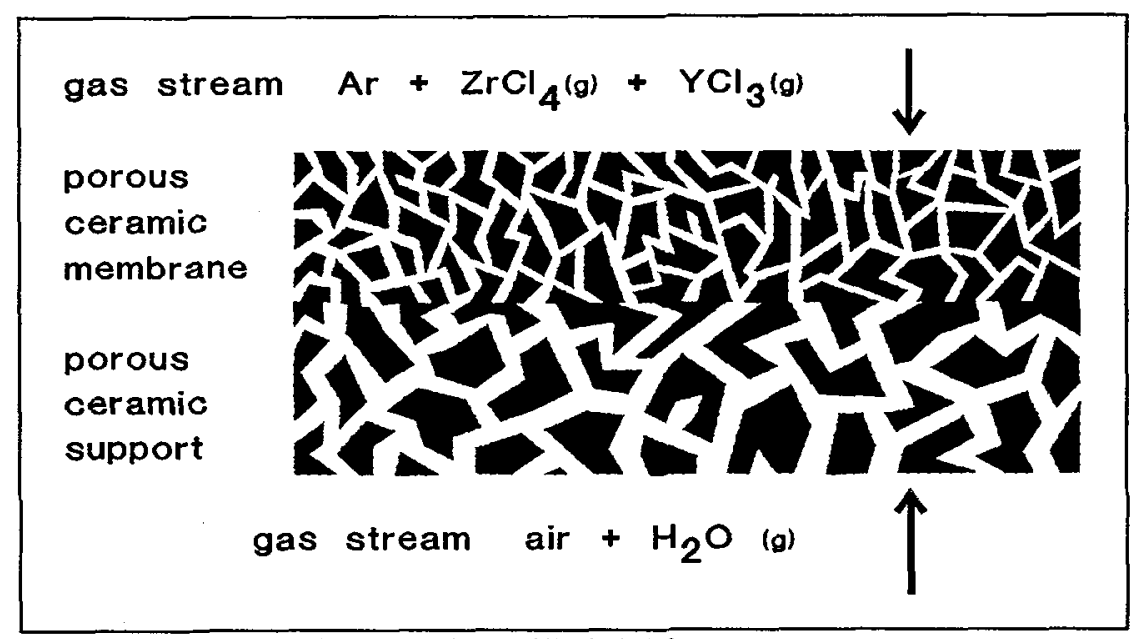

Figure 1. A schematic view of modified CVD process.

chemical reaction would be either a homogeneous or heterogeneous reaction. If the chemical reaction takes place between the reactant molecules in gas phase and the reaction product is then deposited on the inner surface of the pores, this reaction is a homogeneous one. Such a deposition in general is expected to be porous, and it would be very difficult to get pore closure (gas impermeable). If the reactant molecules are first adsorbed onto the inner surface of the pores and then react with each other to form solid oxide(s) directly on the inner surface of the pores, the reaction is a heterogeneous one. The deposition is expected to be a crystalline phase and would result in a pore closure. It is clear that a heterogeneous reaction is desired both for preparation and modification of porous ceramic membranes and for growth an ultrathin gas-tight layer on porous substrates.

This paper presents a study on the reaction kinetics of a CVD process in porous ceramics by both theoretical analysis and experimental approach. Theoretical analysis predicts that the pore size decreases proportionally with an increasing deposition time when the chemical reaction is homogeneous, while the pore size reduces exponentially with an increasing deposition time when the reaction is a homogeneous one. Experimentally the change of pore size of porous ceramic membranes by depositing yttria stabilized zirconia (YSZ) is determined by means of permporometry, a unique technique for measuring the pore size distribution in porous media.

\section{Theoretical analysis}

For the following theoretical analysis three assumptions are made. (1) The porous ceramic substrates are thermally and chemically stable, i.e. no sintering (pore growing and/or removing) and decomposition processes take place during the CVD experiments. This is satisfied experimentally by using thermally stabilized ceramic membranes. (2) The chemical reaction and/or deposition take place inside the pores of the substrates. Such a deposition can be obtained using proper CVD experimental conditions [5,7]. (3) A cylindrical pore model is used for simplicity, of which a schematic view is shown in Figure 2, in which $r$ is the pore radius at the position $z$, where the maximum deposition occurs after a period of deposition time $t ; r_{0}$ is the initial pore radius and $h$ is the length of the pores. 


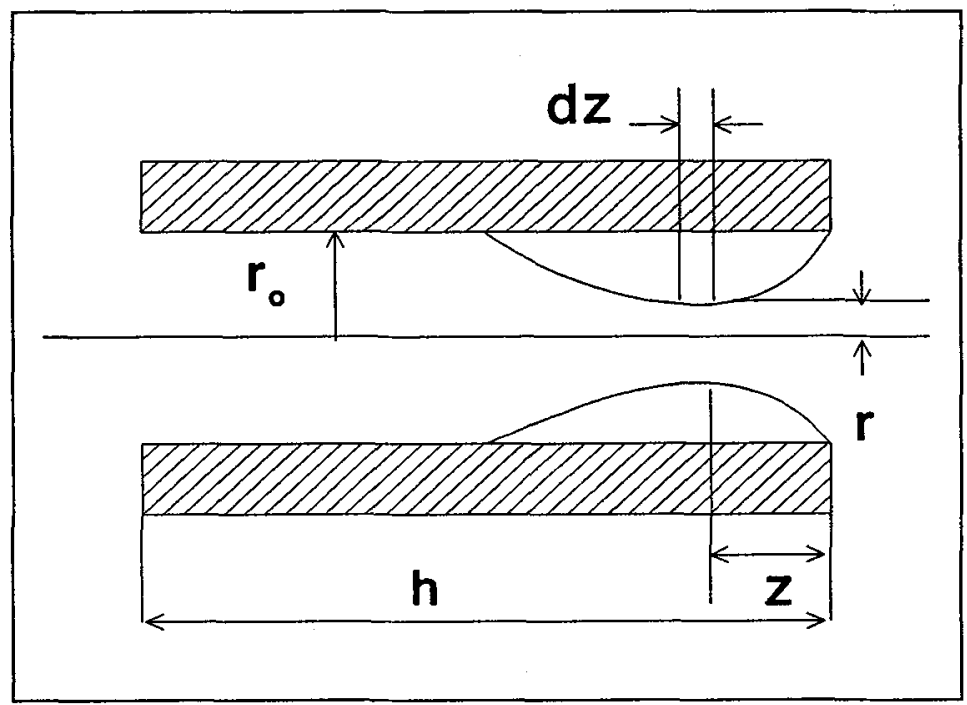

Figure 2. A cylindrical pore model for theoretical analysis of pore narrowing by a CVD process.

\section{Homogeneous reaction}

The chemical reactants meet and react in the gas phase inside the pores, the reaction product then deposits on the surface of pores resulting in pore narrowing. Note that here we ignore the gravity influence on the deposition. For such a chemical reaction the deposition rate is proportional to the pore volume, $\pi \mathrm{r}^{2} \mathrm{dz}$, we have (mass balance):

$$
-2 \pi r d z \frac{d r}{d t}=R_{h o m o} \pi r^{2} d z
$$

here $R_{\text {homo }}$ is the apparent homogeneous reaction rate, which is dependent on the reaction temperature, the concentration of the reactants and their reaction orders. Rearranging and integrating the equation with a boundary condition of $r=r_{0}$ at $t=0$, then we have:

$$
\ln \frac{r}{r_{o}}=-R_{\text {homo }} t
$$

This equation indicates that the pore closure time is infinite, i.e. experimentally it would be very difficult to get pore closure.

\section{Heterogeneous reaction}

In pores within nanometer scale, the gas diffusion inside the pores is in the Knudsen region only heterogeneous reactions are possible. A heterogeneous reaction consists of three processes. The first one is the adsorption of the reactant molecules onto the inner surface of the pores. The second is the chemical reaction between the (adsorbed) molecules on the pore surface (e.g., the LangmuirHinshelwood reaction). And the last is the desorption of the gaseous reaction product(s) from the surface of the pores. Each process can be the rate-limiting step for the deposition of metal oxides. All three processes take place on the inner surface of the pores and thus are (proportionally) related 
to the inner surface area of the pores. Therefore the rate of the deposition is proportional to the inner surface area of the pore, $2 \pi \mathrm{rdz}$, the mass balance is given by:

$$
-2 \pi r d z \frac{d r}{d t}=2 R_{\text {heter }} \pi r d z
$$

Here $R_{\text {heter }}$ is the apparent overall heterogeneous reaction rate, which is dependent on the reaction temperature, the (surface) concentration of the reactants and their reaction orders. Rearranging and integrating this equation with a boundary condition of $r=r_{0}$ at $t=0$, yields:

$$
\frac{r}{r_{o}}=-\frac{R_{\text {heer }} t}{r_{o}}+1
$$

From this equation a pore closure time $t_{c}(a t r=0)$ is given by:

$$
t_{c}=\frac{r_{o}}{R_{\text {hecr }}}
$$

This equation indicates that the pore closure time is proportional to the initial pore size of porous substrates. Note that equation 5 agrees well with that reported previously by Lin et al. [4] using mathematic modelling analysis on the CVD process on porous media.

\section{Experimental}

The CVD experiments are performed in a home made apparatus, of which a schematic diagram is shown in Figure 3. The CVD experimental conditions are given in Table 1 and the details of the experimental procedure are given elsewhere [2,5]. The chemicals used in the CVD experiments are $\mathrm{ZrCl}_{4}\left(99.9 \%, 200\right.$ mesh, CERAC), $\mathrm{YCl}_{3}$ (99.9\%, 60 mesh, CERAC), $\mathrm{H}_{2} \mathrm{O}$ (doubly-distilled), $\mathrm{Ar}$ (99.999\%, UHP 5.0), and Air (Technical grade). Two types of porous ceramic substrates (discs: $12 \mathrm{~mm}$ in diameter and $2 \mathrm{~mm}$ in thickness) are used. Type A substrate is porous $\alpha$-alumina, while type B substrate consists of two layers: an $\alpha$-alumina supporting layer and a La-doped $\gamma$-alumina

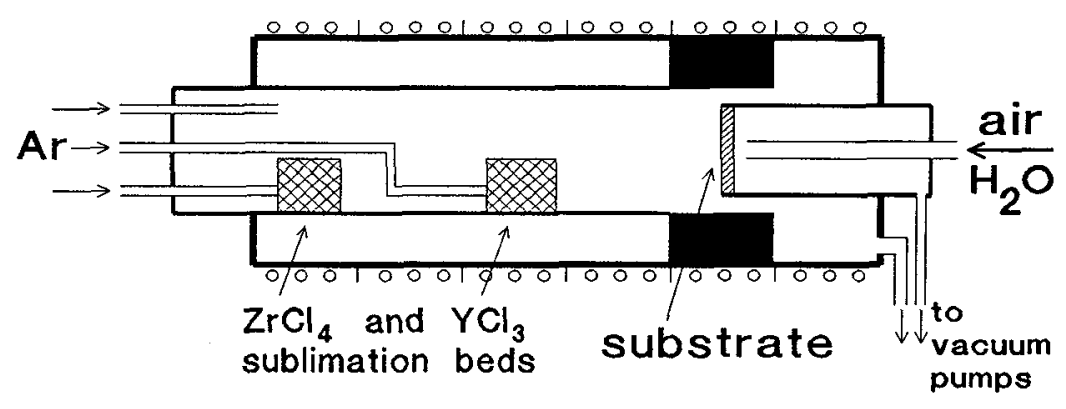

Figure 3. A schematic diagram of the CVD reactor. 
membrane top layer. The $\alpha$-alumina substrate $(2 \mathrm{~mm}$ in thickness) has a porosity of $43 \%$ determined by mercury porosimetry, a mean active pore radius of $35 \mathrm{~nm}$ determined by permporometry. The La-doped $\gamma$-alumina membrane top layer has a porosity of $50 \%$ (nitrogen adsorption-desorption) and a mean active pore radius of $10 \mathrm{~nm}$ (permporometry). The thickness of this top layer is approximately $4 \mu \mathrm{m}$ according to SEM observation. The substrate (both $\alpha$-alumina supporting layer and La-doped $\gamma$-alumina top-layer) is thermally stable, i.e., no sintering and/or pore growing occur, and chemically inert during the CVD experiments.

The reduction of the pore size caused by depositing YSZ was determined by using permporometry. This method is based on the controlled blocking of pores by capillary condensation of a vapour phase (cyclohexane) and the simultaneous measurement of the (oxygen) gas diffusional flux through the remaining open pores. Starting with the saturated vapour pressure all pores in porous substrate are filled and no gas transport through the substrate is possible. When the vapour pressure is reduced, the pores larger than a corresponding size in accordance with the Kelvin equation [8], will open and are available for gas transport. By stepwise decrease of the vapour pressure the gas transport the substrate is measured, from which the active pore size distribution is calculated. The details of the permporometry measurements are presented elsewhere [9].

Table 1. The CVD experimental conditions

$\begin{array}{ll}\text { Substrate temperature } & 800-1000{ }^{\circ} \mathrm{C} \\ \mathrm{ZrCl}_{4} \text { sublimation bed temperature } & 160{ }^{\circ} \mathrm{C} \\ \mathrm{YCl}_{3} \text { sublimation bed temperature } & 640{ }^{\circ} \mathrm{C} \\ \mathrm{YCl}_{3} / \mathrm{ZrCl}_{4} \text { ratio in vapour } & 3 / 10 \\ \mathrm{Reactor} \text { pressure } & 2 \mathrm{mbar}(200 \mathrm{~Pa}) \\ \mathrm{Ar} \text { gas stream through } \mathrm{ZrCl}_{4} \text { bed } & 3 \mathrm{ml}(\mathrm{STP}) / \mathrm{min} \\ \mathrm{Ar} \text { gas stream through } \mathrm{YCl}_{3} \text { bed } & 1.5 \mathrm{ml}(\mathrm{STP}) / \mathrm{min} \\ \text { Total Ar gas stream on chloride side } & 5.5 \mathrm{ml}(\mathrm{STP}) / \mathrm{min} \\ \text { Air stream through } \mathrm{H}_{2} \mathrm{O} \text { sparger } & 0.7 \mathrm{ml}(\mathrm{STP}) / \mathrm{min} \\ \text { Water sparger temperature } & 40{ }^{\circ} \mathrm{C} \\ \text { Total pressure in water sparger } & 150 \mathrm{mbar}(15 \mathrm{kPa})\end{array}$

\section{Results and discussion}

XRD analysis indicates that the deposition on both type A ( $\alpha$-alumina) and B (La-doped $\gamma+\alpha$ alumina) substrates is yttria-zirconia solid solutions consisting of mainly cubic phase with a fluoritetype structure as well as a small fraction of tetragonal and monoclinic phases. The deposition has an overall composition of $\mathrm{Y}: \mathrm{Zr}=17: 83$. SEM/EDS analysis shows that the deposition of yttriazirconia in both type A and B substrates is located inside pores of the substrate with the maximum deposition (concentration) close to the surface from where the metal chloride vapours were supplied. Figure 4 shows the deposition profile in the type B substrate. In this figure, only the deposition profile of zirconium element is presented, since the yttrium and oxygen have a similar deposition profile as zirconium. The CVD deposition was conducted on the type B substrate using the experimental conditions given in Table 1 for 20 min at temperatures $800^{\circ} \mathrm{C}$. The $\mathrm{X}$-axis in this figure is the distance from the surface from where the metal chloride vapours were supplied and the unit of the Y-axis is arbitrary. The deposition width within the type B substrate is approximately $4 \mu \mathrm{m}$, similar to the thickness of the membrane top layer [5,7]. This result suggests that the deposition takes place throughout the membrane thickness with strongly enhanced concentration just below the 


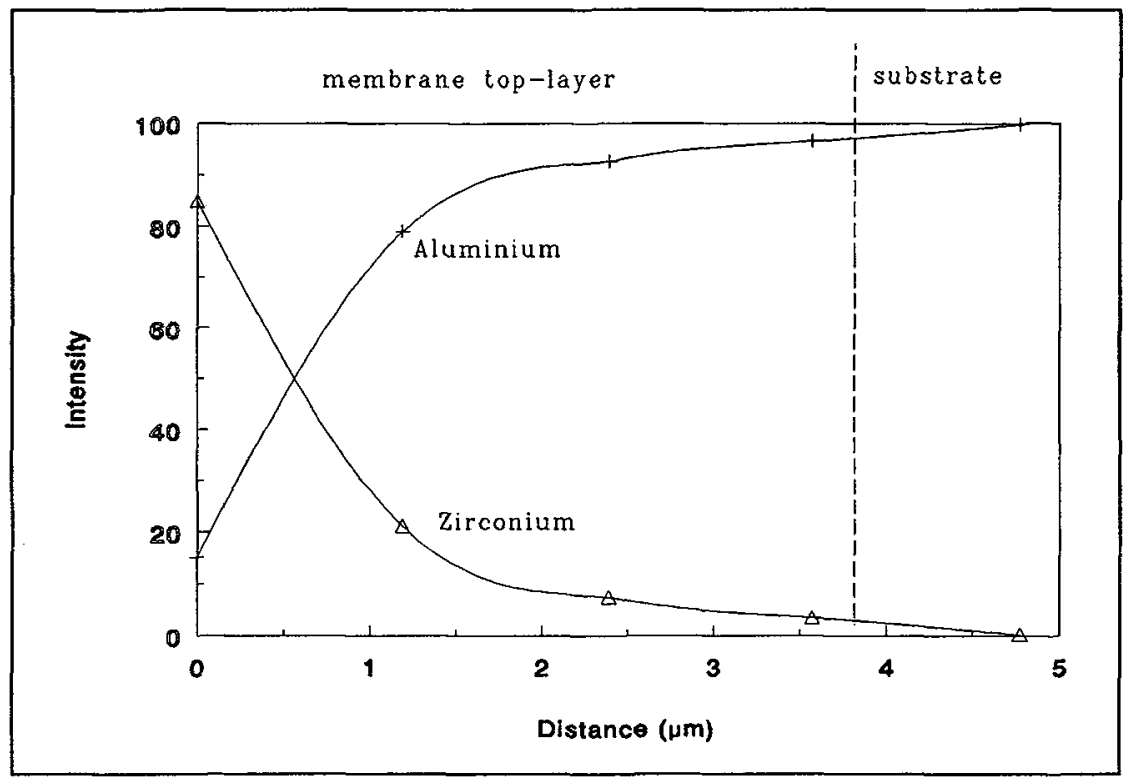

Figure 4. The deposition profile of yttria-zirconia in the type B substrate (20 min CVD at $\mathrm{T}=800^{\circ} \mathrm{C}$ ), determined by SEM/EDS.

pore entrance $(1-2 \mu \mathrm{m})$. The accuracy of the measurement cannot exclude completely the formation of a very thin layer on top of the membrane. The deposition profile in the type A substrate is similar to that in the type B substrate and the width of the deposition zone is approximately $5 \mu \mathrm{m}[5,7]$.

A reduction of the pore size (distribution) was observed on both type A and B substrates by depositing YSZ inside the pores. Figure 5 shows the size distribution of the active pores of the type B substrate before and after 20 min deposition of $Y S Z$ at $800^{\circ} \mathrm{C}$ determined using permporometry. The number averaged mean pore radius was reduced from about $9 \mathrm{~nm}$ to $6 \mathrm{~nm}$, while the oxygen permeation has decreased drastically from $32 \times 10^{-8}$ to $12 \times 10^{-8} \mathrm{~mol} / \mathrm{m}^{2} . \mathrm{s}$. Pa. Besides, in Figure 5 there is also an indication that there were large pores and/or pinholes in the substrates (a long tail of the accumulated oxygen permeation curve at $r>11 \mathrm{~nm}$ ) before CVD experiment and they were eliminated (filled by deposition) after CVD experiment. The elimination of the large pores and/or pinholes from the substrate is probably one of the reason for the drastic decrease of oxygen permeation. Besides the relative large concentration of deposited material just below the entrance edge of the pores would form an additional (very thin) layer on top of the substrate and thus cause an increase of the resistance to the oxygen permeation through the substrate. At this moment, however it is not possible to separate those different contributions. For the type A substrate, after $20 \mathrm{~min}$ deposition at $800^{\circ} \mathrm{C}$, the number averaged mean pore radius has been reduced from about $35 \mathrm{~nm}$ to $20 \mathrm{~nm}$, though the oxygen permeation has been reduced from $41 \times 10^{-8}$ to $39 \times 10^{-8}$ $\mathrm{mol} / \mathrm{m}^{2}$.s.Pa. The small decrease of oxygen permeation is ascribed to the narrow deposition zone of approximately $5 \mu \mathrm{m}$, in comparison with the thickness of the substrate, $2 \mathrm{~mm}$. Pore narrowing occurred in such a small width would result only in a small increase of the diffusion resistance, i.e., a small decrease of oxygen permeation through the substrate. The porosity of the substrate remains almost unchanged.

Figure 6 shows the number averaged mean pore radius in both type $A$ and $B$ substrates as a function of the deposition time (the deposition temperature is $800^{\circ} \mathrm{C}$ ). The pore size was determined by permporometry. By this method only those active pores (effective for gas diffusion) are measured 


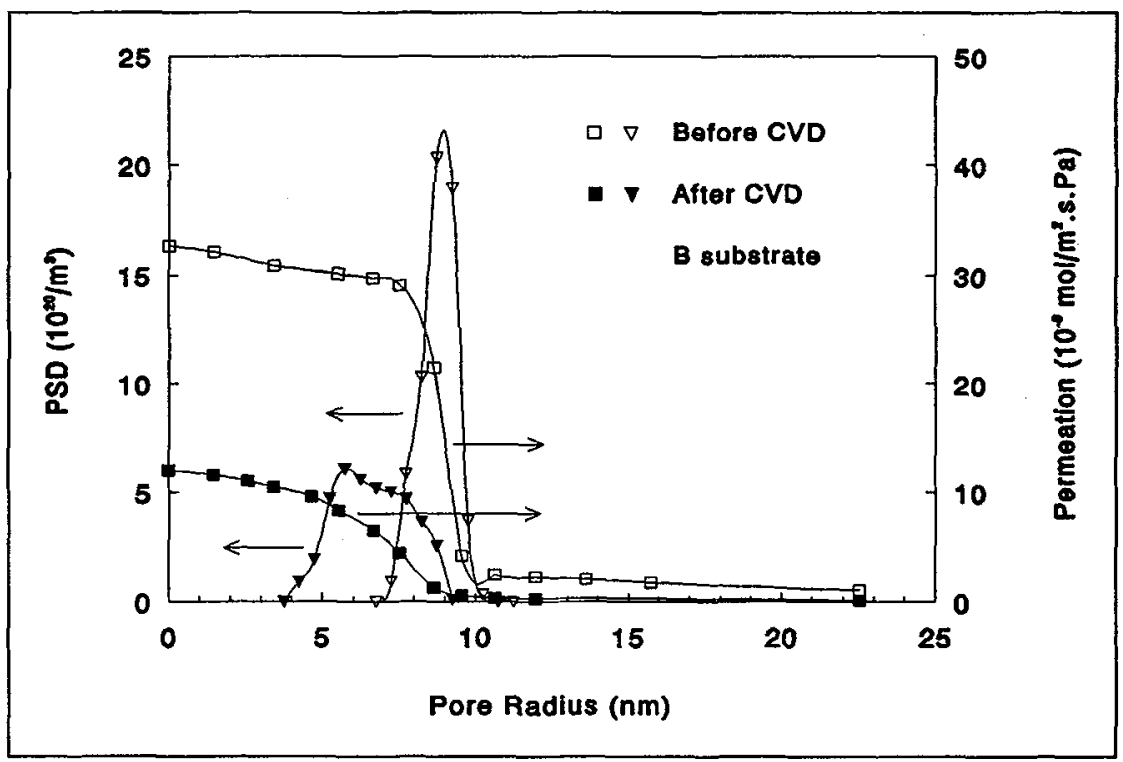

Figure 5. Accumulative oxygen permeation as a function of pore radius and the pore size distribution (PSD) in the type B substrate before and after 20 min deposition of YSZ by means of permporometry.

[9]. In the modified CVD process the deposition mainly occurs in the active pores. Besides in the permporometry measurements only the radius of the narrowest part of each pore is determined. For the porous substrates with deposition inside pores, the narrowest part of each pores is where the maximum deposition is located (seen Figure 2). Figure 6 demonstrates a linear relation between the

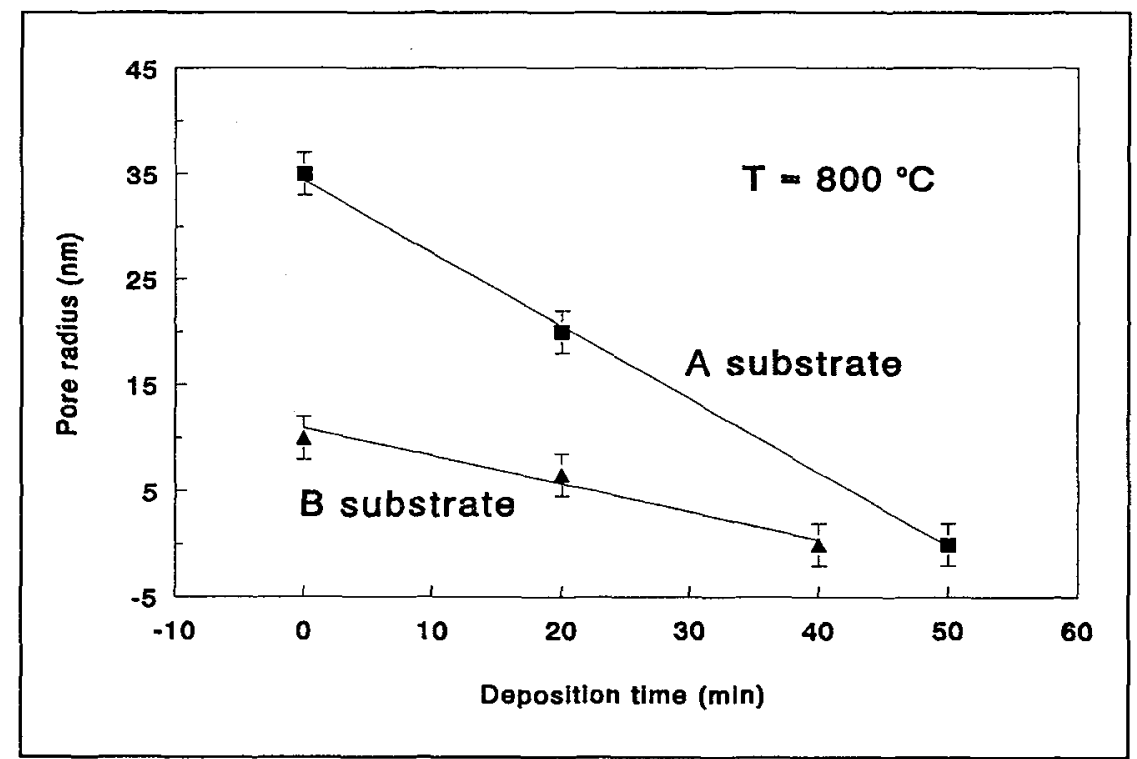

Figure 6. The mean active pore size in both type $A$ and $B$ substrates as a function of deposition time, CVD experiments were done at the conditions given in Table 1. 
mean active pore radius and the deposition time in both type $A$ and $B$ substrates. The pore closure time for the type B substrate is approximately $40 \mathrm{~min}$ and $50 \mathrm{~min}$ for the type A substrate. A linear relation between the pore size and the deposition time and a finite pore closure time imply that the reaction mechanism in the CVD process is a heterogeneous reaction, as indicated previously by theoretical analysis.

Recently Lin et al. [10] have reported experimental studies on the pore size change of porous ceramic membranes (similar to the type A and B substrates used in the present study) after modification by CVD. They have come to a conclusion that the flow averaged active pore size does not decrease while the gas (helium) permeation has been reduced a factor of 10 and 50 for $\alpha$ alumina (the type A) and $\gamma+\alpha$-alumina (the type B) substrates, respectively. However, they have not shown where is the deposition of YSZ located, inside the pores or on top (outside the pores) of the substrates. Such results could be ascribed to the formation of an extra layer by depositing YSZ on top (outside the pores) of substrates by using different CVD conditions from those used in the present study, which would certainly result in an increase of the gas diffusion resistance, i.e., a reduction of gas permeation through the substrates. More detailed discussion is presented previously elsewhere [5,7]. Our experimental results above have demonstrated clearly that the average (active) pore size has been reduced after deposition of YSZ inside the pores with a relative small decrease of oxygen permeation.

\section{Conclusions}

Theoretical analysis and experimental results show that the chemical reaction of metal chloride vapours with water vapour (and oxygen gas) in the modified CVD process on porous ceramic substrates is most probably a heterogeneous reaction. The deposition process results in a mainly cubic yttria stabilized zirconia phase located inside pores. The pore size decreases linearly with an increasing deposition time. A pore closure time was observed of approximately $40 \mathrm{~min}$ for La-doped $\gamma+\alpha$-alumina membrane and $50 \mathrm{~min}$ for $\alpha$-alumina substrates.

\section{References}

[1] Bhave, R. (ed.), Inorganic Membranes: Synthesis, Characterization and Properties, Van Nostrand Reinhold, New York, 1991.

[2] Haart, L.G.J. de, Lin, Y.S., Vries, K.J. de and Burggraaf, A.J., J. Euro. Ceram. Soc., 8(1991)59-70.

[3] Carolan, M. and Michaels, J.N., Solid State Ionics, 25(1987)207-16.

[4] Lin, Y.S. and Burggraaf, A.J., AIChE J., 38(1992)445-54.

[5] Cao, G.Z., Brinkman, H.W., Meijerink, J., Vries, K.J. de and Burggraaf, A.J., J. Amer. Ceram. Soc., (1993), in the press.

[6] Isenberg, A.O., Proc. Symp. Electrode Materials, Processes for Energy Conversion and Storage", eds. McIntyre, J.D.E., Srinivivasan, S. and Will, F.G., The Electrochem. Soc. Inc., Princeton, NJ, Vol 77-6, 1977, pp. 572-83.

[7] Cao, G.Z., Brinkman, H.W., Meijerink, J., Vries, K.J. de and Burggraaf, A.J., Proceedings of Zirconia V, 1992, Melbourne, Australia, in the press.

[8] Gregg, S.J. and Sing, K.S.W., Adsorption, Surface Area and Porosity, 2nd edn., Academic Press, NY, 1982.

[9] Cao, G.Z., Meijerink, J., Brinkman, H.W. and Burggraaf, A.J., J. Membrane Sci., (1993), in the press.

[10] Lin, Y.S. and Burggraaf, A.J., J. Membrane Sci., (1992), in the press. 